\title{
Rethinking Policy and Pedagogy: A Study of Linguistic Diversity and Practice in Sri Lanka
}

Dilini Chamali Walisundara, University of Sri Jayewardenepura

Our country is made of numerous linguistic, ethnic and religious communities. We have to get the best out of all, blend and march forward as a nation and reach the world communities

(First Prime Minister of Independent Sri Lanka, addressing the nation on the $10^{\text {th }}$ of February 1948) $)^{1}$

\section{Introduction}

The existence of diverse ethnic, religious and linguistic communities has been publicly acknowledged in most political fora in Sri Lanka since independence from British colonial rule in 1948 and continues to be a common topic of discussion and debate even today. Most of the rhetoric reflects a political commitment

How to cite this book chapter:

Walisundara, D. C. 2019. Rethinking Policy and Pedagogy: A Study of Linguistic Diversity and Practice in Sri Lanka. In: Wright, C., Harvey, L. and Simpson, J. (eds.) Voices and Practices in Applied Linguistics: Diversifying a Discipline, pp. 161174. York: White Rose University Press. DOI: https://doi.org/10.22599/BAAL1.j. Licence: CC BY-NC 4.0 
towards fostering a culture of acceptance/inclusion at the higher level of policy/planning. In addition, post-independence Sri Lanka has in many instances introduced language policies which have led to strained ethno-linguistic relationships among specific ethnic, religious and linguistic groups, the most well known being the 1956 Swabsha ${ }^{2}$ policy, which led to a divide among the majority Sinhala ethno-linguistic group and other minority ethno-linguistic groups. Subsequent attempts at constitutional reforms in 1977 and amendments to the constitution in 1987 ensured constitutional compliance with the acceptance of Tamil, a minority language, as an official language in Sri Lanka, while establishing English as a link language. In the process and the aftermath of the 30-year conflict, in 2009 policies and decisions that address greater integration among certain ethnicities, religious groups and linguistics communities in conflict have been initiated. This chapter investigates how these policies are clearly manifested in education contexts, particularly at the grass-roots levels - through classrooms and teachers - in order to better understand the impact of government commitment to fostering and enhancing linguistic diversity. This chapter stems from an ongoing study into investigating teacher attitudes and how to foster awareness of linguistic diversity in Sri Lankan classroom contexts.

A recent publication titled People of Sri Lanka: 'Sri Lankan'- Our Identity 'Diversity'- Our Strength by the Ministry of National Integration, Reconciliation and Official Languages, states that Sri Lanka comprises 19 communities. They are Sinhala, Sri Lanka Tamil, the Muslims (Moors), the Tamil community of recent Indian origin, the Colombo Chettis, Sri Lankan Malayalam, Sri Lankan Malay, the Dutch Burgher, the Portuguese Burgher, the Chinese, the Memons, the Coastal Vedda, Sri Lankan Baratha, Sri Lankan Kaffir (the Portuguese Creole-speaking community of African origin), the Dawoodi Bohra, the Vedda, the Sindhi, Sri Lankan Gypsy ${ }^{3}$ and Sri Lankan Parsis. Some of these communities speak their own distinct languages aside from the major languages: Sinhala, Tamil and English. These include Sri Lankan Malayalam and Sri Lankan Malay; the Portuguese Burghers speak Portuguese Creole; the Dawoodi Bohra speak a dialect of Gujarat; the Vedda or the Adivasi speak Vedda language; and the Sri Lankan Gypsies speak a derivation of Teligu.

However, at the national level of representation, particularly in the national census, only nine of these communities (See Table 3) are included despite national-level commitment to the recognition of these communities, their language, religion, social customs and practices.

The contradiction between the census and other governmental policy practices raises many significant questions. The most significant of these is that, while there is a commitment for the representation of these communities at policy level, these minority linguistic and ethnic groups are then absorbed within the larger populations. They are statistically represented only within the larger communities, thereby denying them of any representation at the census level. Finally, the representation of linguistic diversity at school level is another indication of this mismatch between policy and practice (See Table 4). 
Table 3: Distribution of different ethnicities in Sri Lanka.

\begin{tabular}{|l|c|c|}
\hline \multicolumn{1}{|c|}{ Ethnicity } & Population & Percentage \\
\hline Sinhala & $15,250,081$ & 74.9 \\
\hline Sri Lankan Tamil & $2,269,266$ & 11.2 \\
\hline Indian Tamil & 839,504 & 4.1 \\
\hline Sri Lankan Moor & 1,892638 & 9.3 \\
\hline Burgher & 38,293 & 0.2 \\
\hline Malay & 44,130 & 0.2 \\
\hline Sri Lankan Chetti** & 5,595 & 0.0 \\
\hline Baratha $^{* *}$ & 1,717 & 0.0 \\
\hline Others $^{* *}$ & 18,215 & 0.1 \\
\hline
\end{tabular}

Data source: Department of Census Report - 2012

* This includes Dutch, Portuguese and individuals of other European descent.

${ }^{* *}$ Has been included in the census since 2001.

*** This includes the oldest indigenous group and other ethnic, linguistic communities. The Adivasi was a part of the census until 1963 and have since been included in the Other group despite their status as the oldest indigenous community in the country.

Table 4: Language use in schools.

\begin{tabular}{|c|c|c|c|}
\hline S/N & Medium of instruction & No of schools & \% \\
\hline 1 & Sinhala only & 6,338 & 62.3 \\
\hline 2 & Tamil only & 2,989 & 29.4 \\
\hline 3 & Sinhala \& Tamil & 66 & 0.64 \\
\hline 4 & Sinhala \& English & 554 & 5.45 \\
\hline 5 & Tamil \& English & 168 & 1.65 \\
\hline 6 & Sinhala, Tamil \& English & 47 & 0.46 \\
\hline & Total & $\mathbf{1 0 , 1 6 2}$ & $\mathbf{1 0 0}$ \\
\hline
\end{tabular}

Data source: Ministry of Education, Sri Lanka 2016.

According to Table 4, most (91.7\%) of the schools available are monolingual schools, with less availability of bilingual and trilingual schools.

\section{Linguistic diversity: Trends and practices}

The decline of the colonial powers in the mid-twentieth century and the emergence of new independent states in the world clearly laid greater emphasis on 
formulating language policy and planning processes in relation to postcolonial settings, but, as argued by Chimbutane (2015), it was not until the mid-1960s that the movement clearly demarcated itself as a field of research, thereby showing a clear connection between this field of study and decolonisation and multilingualism movements (Chimbutane 2015). Furthermore, against the backdrop of some of the strong colonial ideas that developed well into Westernised sociolinguistics which promoted the view that homogeneity represented modernisation and westernisation while linguistic diversity was an obstacle for national development (Ricento 2000: 198) meant that postcolonial countries had an uphill task of freeing themselves from the debilitating form of Western intellectual imperialism in order to build on the ground realities of postcolonial states, particularly in relation to the ethnic, religious and linguistic diversity that prevailed in these postcolonial countries. Under these circumstances, many postcolonial states like Sri Lanka resorted to the promotion of languages of wider communication (LWC) (Chimbutane 2015) under the influence of Western models of nation formation which promoted monolingual homogenous models. In many instances, LWCs represented the language of the majority ethnic, religious or linguistic group or a globally hegemonic former colonial language like English. The far-reaching ramification of this situation was clearly the 'production and reproduction of social stratification and to increase inequalities in the post-colonial contexts' (Chimbutane 2015: 168) coupled with the use of various labels in reference to varieties of language spoken by minority groups (Gorter and Cenoz 2015):

Minority language' does refer to a specific category of languages, for which sometimes also terms such as 'lesser used, 'heritage, 'stateless', 'indigenous', 'dominated', 'threatened', 'endangered', or 'ethnic' languages are used. Minority languages distinguished from or in opposition to the category 'majority language'; languages that are also referred to as 'dominant', 'national', 'official' or 'state' languages.

(Gorter and Cenoz 2015: 185)

These definitions clearly push these languages into two opposing polarities where one set of definitions represents the mainstream and other more peripheral positions. Mohanty et al. (2009: 284) calls such circumstances 'vicious circle of language disadvantage' and argues that these languages are 'considered inadequate, impoverished and under-developed and, hence unfit for education and scientific use' (Mohanty et al. 2009: 284). In addition, the political and ideological dimension of this issue is that it 'led to the division of languages into different and discrete languages, to a belief that there is a privileged link between people and a territory and to language functioning as autonomous entities in exclusionary relationships with each other' (Hélot 2015: 215). Therefore it is important to identify the factors that influence the position of these languages in their realms of sociopolitical significance. According to Gorter 
and Cenoz (2015), 'language use in the family, protection by the government, provisions in the media, development of a written standard, attitudes towards the language and related identities, levels of activism and ... education, that is schooling in and through the minority language' (p. 187) are such significant influences. As identified, education, particularly schools, become dominant spaces in determining and preservation, language shift and linguistic dominance. Investigating the diverse realities facing educators in multilingual postcolonial classrooms in Sri Lanka thus offers an important opportunity in trying to disentangle some of the complexities identified above.

\section{Data collection and analysis}

The data for this study were collected mostly via questionnaires and informal interviews with teachers and teacher trainers. Others mostly represented the nine provinces of the country. I had a total sample of 82 participants, representing 74 teachers and teacher trainers in English and eight teachers in Sinhala. The questionnaire and interviews attempted to ascertain general information about their awareness of the existence of the different linguistic communities and their general response to the inclusion of such languages in the classroom. For the interviews, I mostly used pseudonyms to ensure the confidentiality of the participants. I report on the major themes emerging in the interview responses, borne out further where relevant by questionnaire data.

\section{Teacher/trainer responses}

\section{Hegemony of dominant languages}

The primary acceptance of this theme arose most clearly from my informal discussions with the members of the teaching community in the number of field visits that I engaged in. For them, either a regional or national language (including English) was seen as highly preferable for educational success, reflecting the known problem of dominant languages hegemonising minority languages.

For example, in a school in a village for Sri Lankan Teligu ${ }^{4}$ speakers, many teachers took a negative view on the use of Teligu, since their perception was that the Teligu-speaking students did not 'perform well' in school. Here is a translated extract.

We speak Tamil and we teach these students in the Tamil medium but they speak a different language; the language they speak at home and as a result we find it very difficult to teach them in Tamil because we have to teach them Tamil first so that they can understand what we are 
teaching them. This is a problem, so now we discourage them from speaking in Teligu in class. They can speak Teligu outside, when they play but inside the classroom they have to speak Tamil.

(Teacher in Teligu-speaking region)

The effect of such linguistic marginalisation can be both cause and effect of social marginalisation and, as a result, the use of these minority languages is found mostly among older members of the communities. In Sri Lanka, there is an established social stigma that surrounds the Sri Lankan Teligu communities, who are sometimes called the 'gypsies or Ahikuntaka or the snake charmers.' This one-time Romani community is no longer nomadic since they have been given housing by the government and local and foreign NGOs. Furthermore, in order to fight the social stigma many of them have converted to Christianity and therefore do not carry any of their original traditional names any more. Their journey towards acceptance in society has resulted in members of these communities embracing a new religion and the transition to using the regional majority language, Tamil, since it is identified as the language of education, opportunity and acceptance. This way Tamil takes precedence over Teligu given the status it holds in the region as well as the country (i.e., the official language status). This will result in the 'speakers of the minority language "shift[ing]" over time to speaking the majority language' (May 2015: 132). At present, as far as we can establish, some of the younger members of the community prefer to use Tamil over Teligu, risking the situation that the language 'may be remembered by a residual group of language speakers, but it is no longer spoken as a wider language of communication' (May 2015: 132) among the group members. Another similarly marginalised group are the Portuguese Creole-speaking African Community (commonly known as the 'Kaffirs') in Sri Lanka, which is currently at a stage of 'language decline' (May 2015: 132), where only the older members of the community are now believed to speak the language.

Gorter and Cenoz (2015: 192) argue that 'multilingualism is generally seen as an asset when it concerns English as a second or third language (for other "big" languages such as French, German or Spanish), but not when it concerns smaller state languages [sic] or regional minority languages.' Many of the respondents who happen to be teachers or teacher trainers echoed similar views.

In Sri Lanka even first languages are not given appropriate recognition in the society. Though they were officially recognized in the eyes of the general public. English is the only language recognized or rather venerated. In other words, there is a social value attached to English unnecessarily making it a class distinguisher.

(Repondent from Wayamba Province) 
Another commented that 'English can act as a link language for all, otherwise it will be a mess if we incorporate all these languages into mainstream education.' This clearly demonstrates a common discussion on what Ramanathan (2015) explains as the challenges posed by the social and economic positioning of English in opposition to home languages and its impact in creating inequalities in society. The key argument of many of the participants in my study was that, while the presence of a globally powerful language means greater access, sometimes this could lead to other languages being sidelined. The important fact here is that, according to one participant, even the official Sri Lankan languages like Sinhala and Tamil seem to be relegated to lower positions of power, placing English as superior, thereby positioning official languages in a hierarchy of symbolic power (Bourdieu 1991).

\section{Recognition in society}

The predicament of many marginal languages in Sri Lanka is reflected in some of the opinions voiced by participants in this study. Many acknowledged a commonly held notion that, given the number of speakers, these languages would receive less recognition. One participant noted that 'these people who speak other languages [referring to the minority languages referred to in the study] are very small in number and they can speak their languages in their homes, since these languages are not required to be learnt for business or interaction.' Further, there were some who claimed that these 'other so-called languages are not encouraged by the state or other institutions.' The views here are in support of an argument where top-down policies are necessary and effective for the sustaining of linguistic diversity in educational settings but tending to assume the view that linguistic diversity is conceptualised on a quantitative basis of number of speakers. This runs contrary to Hélot's (2015) argument on social position, in which positioning minority linguistic communities within the larger discourse of society leads to what Cooke and Simpson (2015) identify as 'Othering or the creation of in-groups and out-groups' (p. 122), where attempts are not made to form a common discourse. Such discourses in postcolonial societies may be representative of notions of nation building and by extension national unity; if so, then use of minority languages may even be seen by some as a threat to the emerging national project. Some of the participants echoed similar views. A participant from the Western Province said that 'these minority languages are not used in common contexts, therefore these languages have no place in society.' However, some of the participants seemed convinced that both quantitative lack of speakers and qualitative social positions of exclusion were connected, making this a problem of the minority communities; they claimed that the problem is rather with 'them' and not with 'us,' as three participants explained: 
A considerable amount of the population speaks Sinhala, Tamil and English. Even the media use these three languages and exposure to other languages is therefore minimal.

(Participant from the Western Province)

Especially the Sri Lankan African Languages are used to get money. This may help them to stand on their own feet but it doesn't help them to preserve their language.

(Participant from the Western Province)

Because those language are spoken by very limited amount of people and those people do not mix with people who speak national languages in Sri Lanka and because they are reluctant to connect with speakers from major languages, their languages will not get proper recognition.

(Participant from the Northern Province)

While many felt that the 'problem' was with the minority language groups, there were others who felt that greater responsibility lay with society in general and other stakeholders. Such views echo the argument that 'language death seldom occurs in communities of wealth and privilege, but rather to the dispossessed and disempowered' (Crawford 1994, cited in May 2015: 133). Some participants from the North Central Province were of the view that 'these languages are not given much attention' and that 'they are not useful in our daily lives,' while another stated 'most of them are not recognized in society and most of them are from lower social strata' and as a result 'these languages are not given much attention.' Further, since 'they can get things done using the dominant languages like Sinhala or Tamil,' these languages can survive alongside by having 'recognition in their own societies.'

Nevertheless, there were also others who felt that these linguistic communities 'add to the linguistic diversity of the country' and 'would contribute to a better communication among the different social groups.' Significant responses for inclusion of linguistic diversity came from the participants from the Eastern Province (a province where some of the minority linguistic communities are located) and also from the Wayamba Province. Two participants from Wayamba Province stated that 'languages depict the culture of any society, so they are a picture of Sri Lanka, its culture and historical aspect.' The participants from the Eastern Province argued that 'most of the people don't know about these different kinds of languages' and as a result 'people look down upon these groups and treat them as if they are inferior to us.' In addition, 'they are not given any opportunity to use their language in public' and 'they are considered as aliens when they speak their language.' Given these responses from the teachers and teacher trainers around the country, it seems that policy-level commitment to linguistic diversity remain inadequate in implementation. For these 
participants, at least, they seemed unaware of the notion that 'language and linguistic diversity should be included in the mainstream curriculum alongside Foreign Language Teaching (FLT) and learners speaking a minority language should see their linguistic competence in their first language acknowledged and valued in the school system' (Hélot 2015: 218).

\section{Language rights}

Given the evidence of marginalisation found in my data, I also wished to investigate the awareness of language rights among the participants. Chimbutane (2015) notes two key trends in relation to multilingual policies and practices in the world: one which looks to promote local and regional languages and the other being the rapidly growing status of English as a global language, as a potential threat to such multilingual promotion. The findings in my data were categorised as general opinions in relation to language rights, expression of interest in legislative initiatives, opinions relating to lack of language rights and the needs to establish such rights. For instance, one participant explained that 'it's a basic human right for people to be able to learn in their mother tongue, which is more comfortable for them, while another argued, 'although Sri Lanka is a multi-lingual, multi-religious and multi-cultural country, all the languages that are being used in Sri Lanka are not given adequate recognition,' thereby emphasising on the importance of ensuring the right to use and preserve these languages. A few participants spoke of the need for legislative action. For instance, one participant explained, 'in Sri Lanka, people speak Sinhala and Tamil languages, and there are villages where languages like Sri Lankan Teligu are spoken but since they are not "visible," they are not accepted by the Sri Lankan constitution.' Therefore, many argued that 'it's the right of these linguistic communities to have the opportunity to speak their own language since we all have a right to speak our mother tongue freely.'

However, despite this awareness, many seemed to have reservations about the practical implications of a broader inclusive policy of linguistic diversity. Some argued that a 'common language will unite people', while 'different languages tend to be divisive as we had experienced' (referring to the 30-year conflict in Sri Lanka). Many agreed that 'more languages create many pockets of divisions.' There also seemed to be a general scepticism towards policies and implementation, as articulated by one participant:

As a country, we still have difficulty in recognizing and implementing the existing language policy nationally. The official language act is just a written document which is not fully implemented. Furthermore, co-existence is only a word as long as one community wants to rule the other. 
These languages are not major languages. These languages do not have recognition all over the country. Besides, we have English as a link language. Veddha and Portuguese Creole are used in different parts of the country. So these languages are only minor languages unlike Sinhala or English.

The general consensus supports the earlier findings that monolingualism or languages of greater quantitative representation had more value and recognition in society as opposed to other quantitatively less visible languages. Further, difference was perceived as a threat to national unity and nation building, while some saw it as a wider representation of diversity. In conclusion, the participants demonstrated a divisive position in the issue of language rights, with some in support of wider representation of diversity and others preferring a more collective uniformed representation with minimal space for diversity.

\section{Classroom situations}

It has been argued that 'pedagogies that build on the linguistic, cultural and sociocognitive resources children bring to school are basic to a quality education that serves local needs as well as the need for a critically conscious and skilled nation and global citizenry' (McCarty \& Nicholas 2015: 151). Therefore schools and classrooms become a centre for any discussion on linguistic diversity. The responses of many of the participants in relation to classroom situations varied. Some took the typical 'indoctrinated' view that these languages 'have no utility value' (Bear Nicholas 2009). For instance, some argued that, 'as there are no teachers who speak other languages, therefore we don't need to address them,' while others considered it to be an unnecessary allocation of resources and money - 'it's expensive to hire teachers to teach these languages' (participants in the Eastern Province), and 'allocating more resources to teach these languages will be useless' (Eastern Province). Contrastingly, there were some who felt that 'languages always help you to go to the world with different skills and knowledge and it's always good to have variety in life to explore more in the world'; this type of attitude would be useful since 'through the exploration of how different languages function, students can be brought to understand the relativity of differences at the linguistic and cultural level and that bi or plurilingual speakers are the very ones who build bridges between people of different cultures' (Hélot 2015: 216). In this context, some participants argued that 'if these languages are introduced into the curriculum, there would be a possibility to preserve them' and cautioned that 'there should be proper organisation if it is to succeed' (Uva Province), indicating an inclination towards the view that linguistic diversity has to do with developing new relationships to language and languages, new understandings of how language is used in society, an awareness of the rights of minority speakers to be educated in their 
home languages and a recognition that many languages in the world today are endangered' (Hélot 2015: 215).

This range of views highlights how far schools may become contested spaces of linguistic opportunity or adversity and/or spaces of acceptance or rejection, particularly in relationships among students who represent majority and minority languages:

A language becomes a different issue when seen from the perspective of the speaker of a socially dominant language or for a speaker of a minority language. For the majority language speaker, it is taken for granted that the language of the home and the language of the school are the same... for a minority language speaker, however, there is frequently a mismatch between the language of the home and the school.

(Gorter and Cenoz 2015: 184)

A similar view was expressed by one of the participants, who felt that providing the opportunity for the students to use their home languages in class would be a reflection of greater empowerment and inclusion since 'there are students whose mother tongue may be Malay, if they are given the opportunity to use it in class, it would make them feel free in their classroom work' (Uva Province). As Hélot (2015) explains, 'one obvious way of opening our classrooms to linguistic diversity would be to include all the languages spoken by pupils at home in the pedagogical activities implemented in schools and to allow bilingual or multilingual [my inclusion] students to use their various languages to learn in class (Hélot 2015: 216).

The predominant role of teacher discourse and its implications in relation to policy implications have been explained (Gombos 2001; Heller 1994) as critical in multilingual settings; they argue that 'teacher discourse may let the student know that the minority language has less value, e.g., for economic advancement, or is less well developed linguistically, or cannot be used for all social domains' (Gombos 2001; Heller 1994). In this sense, it is important to train teachers to be aware of the importance of linguistic diversity in classroom contexts, as identified by a participant who explained that in training, there is no need to focus on linguistic diversity but for classroom teaching it is essential. So the teachers should be instructed to cater to this need.'

\section{Conclusion}

The current study examined the extent to which multilingual and inclusive practices in relation to linguistic diversity can be found in Sri Lanka mainstream classrooms. The study was mainly aimed at investigating the views and opinions of school teachers/trainers on linguistic diversity in Sri Lanka, particularly in relation to 'low-status' (Chimbutane 2015) or 'low-density' 
languages as identified by the current Minister for National Coexistence, Dialogue and Official Languages in Sri Lanka. It was hoped that using data taken from 'bottom-up initiatives' (Chimbutane 2015: 167) would help us comprehend the complexity of implementing policies of linguistic diversity in Sri Lanka. The findings revealed an awareness of these different linguistic groups in society; however, the classrooms were still observed as monolingual spaces and diversity seemed adequate in its symbolic representations at government level through forms of promotional literature or cultural events. Furthermore, many demonstrated a certain level of scepticism in the implementation of policies relating to linguistic diversity owing to popular notions and constructs of national identities that foster a unified identity as opposed to a combination of diverse groups and representations which many argue to promote a divisive status. Clearly there is a long way to go before Sri Lanka can achieve the kind of diversity in teacher thinking that it aims to in its language policies.

\section{Endnotes}

1 Taken from the Message of the Hon. Minister of National Coexistence, Dialogue and Official Languages, published in People of Sri Lanka.

2 Sinhala Only Bill: Sinhala is the language of the majority in Sri Lanka and in 1956, amid great pressure from the nationalists, the government was forced to recognise Sinhala as the national language, causing serious civil unrest among the majority Sinhala and minority communities in the country.

${ }^{3}$ This term is not used any more since it is considered insulting to this community.

4 The Teligu speakers are sometimes referred to as Tulu speaks in Pathmanathan and Endagama (2017) Peoples of Sri Lanka. However, Hettiarachchi (1965) in Sinhala Vishwakoshaya (Sinhala Encyclopedia) states that they are in fact speakers of Teligu or a derivation of Teligu speakers in Sri Lanka. Furthermore, Tulu has been identified as a Kannada language.

\section{References}

Bear Nicholas, A. 2009 Reversing language shift through a native language immersion teacher training programme in Canada. In Skutnabb-Kangas, T., Phillipson, R., Mohanty, A.K. and Panda, M. (eds), Social justice through multilingual education. Bristol: Multilingual Matters.

Bourdieu, P. 1991 Language and Symbolic Power. Cambridge: Polity Press (English-language edition).

Chimbutane, F. 2015 Multilingualism in education in post-colonial contexts: A special focus on Sub-Saharan Africa. In Martin-Jones, M., Blackledge, 
A. and Creese, A. The Routledge handbook of multilingualism. Abingdon, Oxon: Routledge. pp. 167-183.

Cooke, M. and Simpson, J. 2015 Discourses about linguistic diversity. In Martin-Jones, M., Blackledge, A. and Creese, A. The Routledge handbook of multilingualism. Abingdon, Oxon: Routledge. pp. 116-130.

Crawford, J. 1994 Endangered Native American languages: What is to be done and why? Journal of Navajo Education, 11(3): 3-11.

Department of Census and Statistics, Sri Lanka 2012 Census of population and housing 2012- Final report. Colombo: Department of Census and Statistics.

Gombos, G. 2001 The message of code-switching. Trilingual kindergarten education in a minority context. Paper Presented at the 2nd International Conference on Third Language Acquistion and Trilingualism. Leeuwarden, Fryske Akademy, the Netherlands, 13-15 September.

Gorter, D. and Cenoz, J. 2015 Regional minorities, education and language revitalization. In Martin-Jones, M., Blackledge, A. and Creese, A. The Routledge handbook of multilingualism. Abingdon, Oxon: Routledge. pp. 184-199.

Heller, M. 1994 Crosswords: Language, education and ethnicity in French Ontario. Berlin: Mouton de Gruyter.

Hélot, C. 2015 Linguistic Diversity and Education. In Martin-Jones, M., Blackledge, A. and Creese, A. The Routledge handbook of multilingualism. Abingdon, Oxon: Routledge. pp. 214-231.

Hettiarachchi, D.E. 1965 Sinhala Vishwakoshaya. Volume II. Colombo: Department of Cultural Affairs.

May, S. 2015 Language rights: Promoting civic multilingualism. In MartinJones, M., Blackledge, A. and Creese, A. The Routledge handbook of multilingualism. Abingdon, Oxon: Routledge. pp. 131-142.

McCarty, T.L and Nicholas, S.E. 2015 Indigenous education: Local and global perspectives. In Martin-Jones, M., Blackledge, A. and Creese, A. The Routledge handbook of multilingualism. Abingdon, Oxon: Routledge. pp. 145-166.

Menken, K. and Garcia, O. 2010 Negotiating language policy in schools: Educators as policy makers. New York: Lawrence Erlbaum/Taylor \& Francis/ Routledge.

Ministry of Education, Sri Lanka 2016 Basic information on government schools 2016. Colombo: Statistics Branch, Ministry of Education. Available at http://www.moe.gov.lk/english/index.php?option=com_content\&view=art icle\&id=1220\&Itemid=922 [Last accessed 30 January 2018].

Mohanty, A.K., Mishra, M.K., Reddy, N.U. and Ramesh, G. 2009 Overcoming the language barrier for tribal children: Multilingual education in Andhra Pradesh and Orissa, India. In Skutnabb-Kangas, T., Phillipson, R., Mohanty, A.K. and Panda, M. (eds), Social justice through multilingual education. Bristol: Multilingual Matters. pp. 284-300.

Pathmanathan, S. and Endagama, M. (eds) 2017 People of Sri Lanka: 'Sri Lankan'- Our Identity 'Diversity'- Our Strength. Colombo: The Ministry of National Coexistence, Dialogue and Official Languages. 
Skutnabb-Kangas, T., Phillipson, R., Mohanty, A.K. and Panda, M. (eds) 2009 Social justice through multilingual education. Bristol: Multilingual Matters.

Ramanathan, V. 2015 Rethinking discourses around the 'English-cosmopolitan' correlation: Scenes from formal and informal multilingual educational contexts. In Martin-Jones, M., Blackledge, A. and Creese, A. The Routledge handbook of multilingualism. Abingdon, Oxon: Routledge. pp. 66-82.

Ricento, T. 2000 Historical and theoretical perspectives in language policy and planning. Journal of Sociolinguistics, 4(2): 196-213.

Young, I.M. 1990 Justice and the politics of difference. Princeton, NJ: Princeton University Press. 